By a special tilting arrangement the table can be adjusted at any desired angle. It is provided with marginal sights, and adjustable rules which can be raised by screws or depressed level with the surface of the board. The magnetic compass box is of the shape of a figure 8 , and the card is only graduated for $45^{\circ}$ on each side of the north-south line. It is the most perfectly designed and executed plane-table which we have seen. Two note-books show that he was instructing his sons Ralph and Samuel in the art of surveying in 1773 and 1778 respectively. Ralph Thompson also became an accomplished surveyor, and an example of his work made in 1812, a survey of the Roman town of Manduessedum on Watling Street, is reproduced in Nichols's "Leicestershire".

\section{Nest-Building of Brush-Turkeys}

An early visit to the gardens of the Zoological Society of London is recommended in order to inspect the initial stages in the nest-building of the brush-turkeys, on the north bank of the Canal. The labour of forming the vast mound of leaves, in the centre of which the eggs are laid, is performed by the male. Here they are left until they hatch by the heat generated by the fermentation. The eggs being of great size in proportion to the size of the bird, the early, 'nestling-down', stage is passed within the shell, the down being shed before hatching. By the time this takes place the birds are strong enough to force their way out, and emerge with fully developed flight-feathers. This singular phase in the infancy of birds is confined to the Megapodes, of which there are many species. But some bury the eggs in hot sand, instead of decaying vegetation. The recently added 'piping-crows' from Australia, which are more nearly related to the drongos and swallow-shrikes than to the crows, and that singular fish the climbing-perch (Anabas), are also worth a visit.

\section{Physical Nature of the Nerve Impuise}

AT the Friday evening discourse held at the Royal Institution on February 10, Prof. A. V. Hill discussed the physical nature of the nerve impulse. The properties of the nervous system are based upon a certain transmitted wave which is known as the nervous impulse. This wave, which is a few centimetres long, travels in nerve fibres of the order of $0.01 \mathrm{~mm}$. in diameter with velocities varying from a few centimetres to $100 \mathrm{~m}$. per second. Its nature is not yet understood, but it possesses certain welldefined physical characteristics. The chief difficulty in investigating it is the minuteness of the changes involved in its passage: there is, for example, a rise of temperature, but this is only of the order of one ten-millionth of a degree for each impulse, while the ohemical changes which accompany this are at present altogether beyond detection. Fortunately, owing to the development of modern electrical methods, the electrical accompaniments of the wave can be accurately recorded, and the study of the so-called 'action current' has thrown much light on the process. The nature of electrical excitation has been discussed for many years, and it seems that 'activity' is produced when thecurrent through thenerve fibre surface exceeds a certain value at the cathode. The 'activity' seems to consist of an alteration in the physico-chemical properties of the surface layer, allowing reaction to take place momentarily between inside and outside. The change is rapidly reversed, and the nerve is then ready to transmit another impulse. The passage of the wave involves the liberation of energy during, but chiefly after, the active process. Recovery lasts 30-50 minutes and requires oxygen. In other respects, however, the nerve impulse possesses wave-like properties, and its further investigation by physical means is likely to lead to a far greater understanding of nervous processes and of the phenomena of living activity in general.

\section{Scientific Progress and Ethics}

IN the Journal of the University of Bombay (Sept. 1932), under the title "Is Man Ethically Fit for the Bounties of Science ?" Prof. D. D. Kanga of Gujarat College, Ahmedabad, comments on a convocation address by Sir C. V. Raman on the study of science. Asserting that true scholarship goes hand in hand with research, independence of thought and original thinking, Sir C. V. Raman said that the function of a university is the encouragement of the human intellect and the human spirit in their highest manifestations. The greatest value of science lies not so much in the imparting of knowledge about natural phenomena and the laws of Nature, as in the teaching of the scientific method which has served as a powerful weapon in the hands of man in the discovery of truth and has given him a new view of the universe he lives in. If the same method were used in the problems of daily life, whether political, industrial, social, educational, or religious, it would usher in a new era of progress and enlightenment in all the departments of life. Prof. D. D. Kanga, reviewing the sabotage which has accompanied increased productivity consequent upon the application of modern science, directs attention once more to the problem of distribution, which he reminds us is largely a matter of the individual will. It is the duty of every university to see that the advance of science and the spread of scientific culture go with a parallel advance in man's ethical and spiritual development. The motto of science should be truth and service, and the alumni of a university should be characterised alike by their ability to apply the scientific method in all problems of life and also, in Prof. Kanga's view, by their readiness to share their knowledge, wealth, power and possessions with others, of whatever race or country, for the common good.

\section{Persepolis}

THE archæological expedition to Persepolis of the Oriental Institute of the University of Chicago, one of the eleven expeditions of the Institute now at work in the East, has achieved some remarkable results in its second season's work on the site. Indeed, Dr. J. H. Breasted, director of the Institute, in a comment appended to an abstract of the report by 